\title{
Protein-Metal Interactions of Calmodulin and $\alpha$-Synuclein Monitored by Selective Noncovalent Adduct Protein Probing Mass Spectrometry
}

\author{
Tony Ly and Ryan R. Julian \\ Department of Chemistry, University of California-Riverside, Riverside, California, USA
}

The@netal@inding@roperties@f@roteins@re@iologically@ignificant,@articularly@n@elationship@o@he@molecular@rigins@f@isease@nd@he@discovery@f@herapeutic@pharmaceutical treatments.đHerein,@e@emonstrate@hat@elective@oncovalent@dduct@rotein@robing@nass spectrometry@(SNAPP-MS)đs@esensitive@echnique@to@investigate@the@structural@effects@f protein-metal@nteractions.@We@tilize@pecific,@oncovalent@nteractions@etween $₫ 8$-crown-6 ether $(18 C 6) @ n d(y$ sine $\oplus \circ @$ robe@rotein@tructure@n@he@resence@nd@bsence@f@netal@ons.

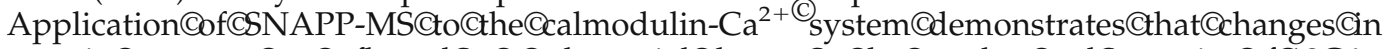
protein@tructure@re@eflected@n@@ubstantial@hange@n@he@umber@nd@ntensity@f(8C6s,

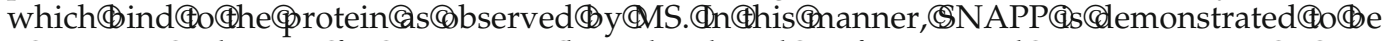
a@ensitive@echnique@or@monitoring@igand-induced@onformational@earrangements@n@proteins.CnCaddition, $\mathbb{C S N A P P ণ i s @ w e l l - s u i t e d @ t o @ e x a m i n e @ t h e @ p r o p e r t i e s @ o f @ n a t i v e l y @ u n f o l d e d ~}$ proteins,@here@tructural@hanges@re@nore@ifficult@o@etect(y@ther@nethods.๑or@xample,

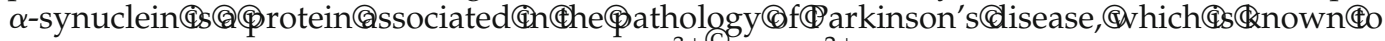

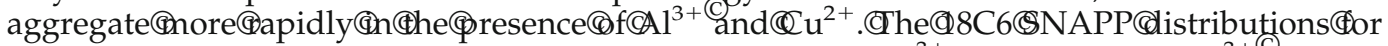
$\alpha$-synuclein@hange@ramatically@n@he@resence@f(3) $\mathrm{M} \mathrm{Al}^{3+}$, @evealing@hat $\mathrm{Al}^{3+} \mathrm{Q}_{\text {binding }}$ causes@@ignificant@hange@n@he@onformational@ynamics@f@he@monomeric $₫$ orm@f@his

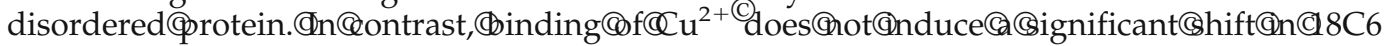
binding,@uggesting@hat@oteworthy@tructural@eorganizations@t@he@monomeric@evel@re minimal@ $\$$ hese@esults@re@onsistent@ith@he@dea@hat@he@netal-induced@ggregation@aused

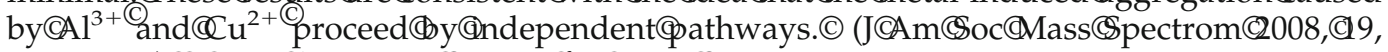
1663-1672)@(2008@American(\$ocietyథror@Mass@spectrometry

$\mathrm{P}$ roperథrotein@unction@s@eterminedథy@@ariety of@factors@including@primary@sequence, (Othreedimensional@tructure, $@$ and@inding@f@ssential ligands.CThe@nterdependence@f@tructure@nd@igand

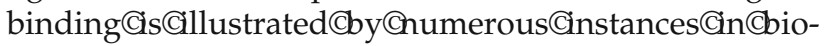
chemistry@wheređigand@ittachment@onfers@iological function.థor@xample,@ssociation@f@alcium@ons@ith calmodulin@induces $@ a @ s t r u c t u r a l @ r e a r r a n g e m e n t @$ that reveals@象ey@ydrophobic@@elix,@hich@an@ecognize and@ind@o@ther@roteins,@1timately@ignaling@nzymatic@phosphorylation@of@the@substrateđ[1,2].CThus, calmodulin@cts@s@n@ntracellular@ $\mathrm{a}^{2+}{ }_{\text {Sensor, }} @$ narking@proteins@for@phosphorylation@only@when $@ \mathrm{Ca}^{2+} \mathbb{C}_{1 \mathrm{~S}}$ bound.

Ligandథinding@an@lso@induce@tructural $₫$ ransitions in@proteins@hat@are@undesirable@and@may@ventually lead@to@he@formation@of@protein@aggregates@hat@are associated@with@several@diseases.CThe@pathologies@of Alzheimer's@disease@[3],®arkinson's@disease@4],@and

Address reprint requests to Dr. R. R. Julian, Department of Chemistry, University of California-Riverside, 900 University Ave., Riverside, CA 92521,@SA.®E-mail:@yan.julian@ucr.edu
Creutzfeldt-Jakob@iseaseథ5]@ređinked@o@xtracellular aggregation@f@therwise@armless@eural@roteins.@ne

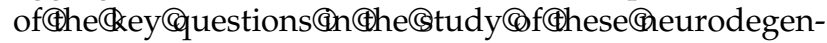
erative@iseases@s:@hat@auses@ormally@unctioning proteins@to@aggregate?CThere@are@several@actors@that have@een@ssociated@ith@rotein@ggregation, (ancluding@ite@pecific@nutations $₫ 6, \mathbb{( \mathbb { 8 } ] , \$ p r o t e i n @ x i d a t i o n} థ 8]$,

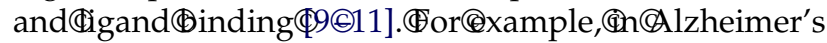
disease $₫ t \oplus$ as@een@hown $\oplus$ hat $(\mathrm{n}$ creased@evels@f@netals such@s@ $\mathrm{u}^{2+}$ and $\mathbb{Z} \mathrm{n}^{2+}$ areథinkedథo@ggregation@f@ $\beta$ protein@in@vitro@[12].๑The@theory@of@metal@induced aggregation Chas@ained@redence@ollowing@umerous studies@ying@metal@oncentrations@in@the@brain@with Alzheimer's@isease@n@ivoథ9].

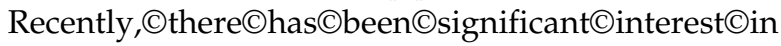
$\alpha$-synuclein, $\mathrm{Ca} @$ protein $\cong$ hat@is@suspected@to@play@an essential role in the pathology of Parkinson's disease [13]. $\alpha$-Synuclein is the major component of Lewy bodies, (for a comprehensive review, see [14]), which are protein aggregates found in the neuronal and glial cytoplasm of patients affected with Parkinson's disease [15], dementia [16], and a specific variant of Alzheimer's disease [17]. Perhaps the most convincing evi- 
dence to date that links $\alpha$-synuclein with the onset of Parkinson's disease is the discovery that single point mutations in the gene that codes for $\alpha$-synuclein increases the likelihood of manifesting Parkinson's disease to $85 \%[18,19] . \alpha$-Synuclein is found naturally in the cytosol and presynaptic terminals of neurons. A complete understanding of the biological function of $\alpha$-synuclein remains a significant challenge. It has been shown that synelfin, an $\alpha$-synuclein homolog found in zebra finches, is up-regulated during song-learning, which suggests that the protein is involved in neuronal plasticity [20]. Additionally, $\alpha$-synuclein has been implicated in biochemical pathways involving neuronal cell apoptosis [21], regulation of dopamine [22], and molecular chaperoning [23].

$\alpha$-Synuclein is a natively disordered protein and adopts a wide distribution of conformations [24]. Commonly used techniques to determine protein structure, such as X-ray crystallography, are inappropriate for disordered proteins like $\alpha$-synuclein. Therefore, studies of $\alpha$-synuclein have typically relied on techniques that report data averaged over the entire ensemble of conformations. For example, using fluorescence, UV/Vis spectroscopy and far-UV circular dichroism, Fink et al. found that metal cations bind to $\alpha$-synuclein and accelerate fibril formation in vitro [11]. Among the most effective metals at accelerating aggregation were $\mathrm{Al}^{3+}$ and $\mathrm{Cu}^{2+}$. In a separate study by Fernandez et al., the putative $\mathrm{Cu}^{2+}$ binding sites were localized to near residue-specific detail using nuclear magnetic resonance spectroscopy [25]. Recently, it was shown that time-resolved fluorescence energy-transfer experiments with $\alpha$-synuclein can effectively separate and identify unique conformations in the ensemble due to differences in inter-residue distances and contact rates [26]. Results from these experiments have demonstrated that the protein is highly dynamic. Fast interchange between conformations occurs even among $\alpha$-synuclein mutants where the rate of protein aggregation is significantly accelerated. Thus, it is very difficult to examine the different conformational states independently without sophisticated instrumentation and introduction of non-native fluorescence energy-transfer donor-acceptor pairs. Fortunately, separation by conformation occurs automatically in the course of electrospray (ESI) [27] MS experiments, as is discussed in more detail below.

A number of approaches utilizing mass spectrometry have been developed to examine protein structure (for a review see [28]). Typically, these techniques use chemical reactions to label specific functional groups on the protein with covalently attached mass tags. The number of functional groups available for covalent modification is dependent on the protein conformation and the chemical environment surrounding each reactive group. This allows mass spectrometry to distinguish between different protein conformations. Perhaps the simplest covalent modification observed in conjunction with mass spectrometry to examine protein structure is protonation. Basic residues such as arginine, lysine, and histidine are expected to be protonated first, followed by protonation at other sites. The basicity of these secondary protonation sites may be enhanced by multidentate interactions with the protein backbone, which stabilizes the charge [29]. A number of reports have been published on the dependency of protein charge state distribution on conformations found in solution using ESI-MS [30-32]. The number of charges that can be placed on a protein is dependent on its conformation and is limited by Coulombic repulsion. Indeed, recently it was reported that the charge state distribution correlates well to the surface area of a protein [33]. Nevertheless, charge state distributions report only the approximate size of a protein in an indirect fashion, meaning that only dramatic changes can be reliably ascribed to structural transitions.

Covalent chemistry can also be tailored to target specific functional groups of a protein. These reactions have been applied extensively in cross-linking studies [34-38], where length constraints imposed by the crosslinking reagent can provide approximate distances between reactive functional groups. Hydrogen-deuterium exchange mass spectrometry (HDX MS) is another approach to examine conformational changes in proteins [39-42]. For example, Gross et al. found that the number of exchangeable hydrogens decreases as the concentration of $\mathrm{Ca}^{2+}$ is increased up to $\sim 0.25 \mathrm{mM}$, which they interpret as a tightening of the $\mathrm{Ca}^{2+}$ binding domains of calmodulin [43, 44]. Reactive labeling groups can also be used to monitor protein surface structure [45]. Specific, noncovalent interactions with the side-chains of proteins can also be used to probe protein structure [46-50].

Selective noncovalent adduct protein probing mass spectrometry (SNAPP-MS) was recently developed to examine the structure of proteins [47-49]. The technique relies on the selective association of 18-crown-6 ether (18C6) with the side-chain of lysine [51]. The noncovalent interaction between $18 \mathrm{C} 6$ and lysine is weak in solution [52], permitting sensitive sampling of the chemical microenvironment surrounding each lysine. Lysine side-chains involved in intramolecular interactions, like hydrogen bonds and salt-bridges, do not bind well to 18C6 [48]. Modulation of these interactions, due to structural rearrangements, typically changes the overall lysine availability for the protein. Once 18C6protein complexes are transferred into the gas phase by ESI, 18C6 strongly associates with the side-chain of lysine, effectively preserving equilibrium solution phase information for subsequent MS detection [50]. The resulting mass spectra reveal a distribution of protein-18C6 complexes (or SNAPP distribution) for each charge state of the protein. Previous work suggests that the intensities and shapes of these SNAPP distributions are the result of statistical averaging of $18 \mathrm{C} 6$ attachment to many potential binding sites. Modulation of the lysine availability at any of these sites due to structural shifts or ligand binding will be easily observed by comparison with the unperturbed protein. In 
addition, sample preparation for a typical SNAPP-MS experiment is simple, requiring only addition of 18C6 and protein to a suitable solvent, followed by ESI-MS.

Herein, we demonstrate that SNAPP-MS is sensitive to conformational changes due to protein-metal interactions in calmodulin and $\alpha$-synuclein. We have examined conformational changes in calmodulin due to $\mathrm{Ca}^{2+}$ binding and found that our SNAPP-MS results agree with the known structures for apo- and holocalmodulin. For $\alpha$-synuclein, where the effects of metal binding are not completely understood, we have examined the effect of biologically relevant $(\mu \mathrm{M})$ concentrations of copper and aluminum. We find that both copper and aluminum bind to $\alpha$-synuclein, but only aluminum causes a significant change in the lysine availability. This change in lysine availability may reflect a shift in the conformational dynamics of $\alpha$-synuclein to aggregateprone structures. Comparison of results with both $\mathrm{Al}^{3+}$ and $\mathrm{Cu}^{2+}$ reveal that the metals accelerate $\alpha$-synuclein aggregation by independent mechanisms.

\section{Materials and Methods}

Calcium acetate (Mallinckrodt Baker, Phillipsburg, NJ), acetic acid (EMD Biosciences, Gibbstown, NJ), aluminum chloride (Sigma Aldrich, St. Louis, MO), and copper(II) chloride (Sigma Aldrich) were of analytical grade and used without further purification. Water was purified to $18.2 \mathrm{M} \Omega$ resistivity using a Millipore Direct-Q (Billerica, MA). Porcine calmodulin was purchased from Ocean Biologics (Corvallis, OR). Recombinant human $\alpha$-synuclein (rPeptide, Bogart, GA) was further purified by dialysis against $\mathrm{H}_{2} \mathrm{O}$ and lyophilized. Stock solutions of calcium acetate were neutralized with acetic acid before addition to protein. Samples contained 10 and $3 \mu \mathrm{M}$ protein for calmodulin and $\alpha$-synuclein experiments, respectively. For SNAPP experiments, a concentration of $18 \mathrm{C} 6$ equal to two times the number of lysines was used to ensure stoichiometric excess of 18C6. For calmodulin, which has eight lysine residues, the concentration of $18 \mathrm{C} 6$ used was $160 \mu \mathrm{M}$. For $\alpha$-synuclein, which has 15 lysine residues, the concentration of $18 \mathrm{C} 6$ was $90 \mu \mathrm{M}$. Replicate sample solutions were spiked with the appropriate metal cation to test for protein-ligand binding. To form holocalmodulin, the calmodulin-18C6 solutions mentioned above were spiked with $\mathrm{Ca}(\mathrm{OAc})_{2}$ to give a final concentration of $25 \mu \mathrm{M} \mathrm{Ca}^{2+}$. To test the effects of metals on $\alpha$-synuclein, solutions containing both $\alpha$-synuclein18C6 were spiked with either $\mathrm{AlCl}_{3}$ or $\mathrm{CuCl}_{2}$ to give final concentrations of $3 \mu \mathrm{M} \mathrm{AlCl}$ or $100 \mu \mathrm{M} \mathrm{CuCl}_{2}$, respectively. All samples were of neutral $\mathrm{pH}$ by litmus paper.

Mass spectra were obtained using an LTQ linear ion trap mass spectrometer (Thermo Fisher, Waltham, MA) equipped with a standard electrospray source. For each protein, voltages, sheath gas flow rates, and temperatures in the source region were optimized for observation of noncovalent complexes, and are similar to pa- rameters described previously [48]. Once optimized, these parameters remained unchanged for all experiments for that protein. The following are typical source parameters: spray voltage $4.5 \mathrm{kV}$, tube lens $150 \mathrm{~V}$, capillary temperature $215^{\circ} \mathrm{C}$, capillary voltage $40 \mathrm{~V}$. For calmodulin, the capillary temperature was raised to $285^{\circ} \mathrm{C}$.

\section{Results and Discussion}

\section{Calmodulin}

The structure of calmodulin has been described as a "dumbbell" shape because it contains two globular domains bridged by an $\alpha$ helical linker [1]. Each globular domain has two EF-hand structural motifs, which are high affinity binding sites for $\mathrm{Ca}^{2+}$ ions [53-55]. Figure 1a shows the mass spectrum obtained from a solution containing apocalmodulin and 18C6. A statistical distribution of $18 \mathrm{C} 6$ adducts is observed for each charge state. The number of $18 \mathrm{C} 6 \mathrm{~s}$ that bind to calmodulin decreases with increasing charge state. This observation is highly unusual and would seem to indicate that more extended structures lead to reduced lysine availability. Examination of the sequence of calmodulin suggests a possible explanation. Six out of the eight lysine residues of calmodulin are adjacent in sequence to an acidic residue. This means that as the protein unfolds, each lysine remains in close proximity to an acidic residue, which can interfere with attachment of 18 C6.

The most abundant peak observed for any charge state is calmodulin with no 18C6 attached even though $18 \mathrm{C} 6$ is present in significant excess in solution. This result is consistent with previous observations [48], and is due to the presence of interfering intramolecular interactions restricting lysine availability. A zoomed-in view of the +12 charge state is shown in Figure 1b. The peaks with asterisks are 18C6 adducts of calmodulin dimer, which is present in minor abundance. Noncovalent dimers of calmodulin have been observed previously in ESI mass spectra at similar concentrations of protein $[56,57]$. These dimers have been shown to exist in solution, and are not simply an experimental artifact due to the ionization process [56].

To test whether SNAPP-MS can detect a conformational change due to metal binding, a 2.5-fold excess of $\mathrm{Ca}^{2+}$ was added. Calmodulin binds up to four calcium ions with the following association constants: $1.0 \times 10^{7}$ $\mathrm{M}^{-1}, 3.98 \times 10^{7} \mathrm{M}^{-1}, 3.16 \times 10^{6} \mathrm{M}^{-1}$, and $2.51 \times 10^{6}$ $\mathrm{M}^{-1}$ [58]. In comparison, association constants determined for $18 \mathrm{C} 6$ and $\mathrm{Ca}^{2+}\left(\mathrm{K}=3.39 \mathrm{M}^{-1}\right.$ to $\left.5.01 \mathrm{M}^{-1}\right)$ are much smaller, and indicate that competitive binding of $\mathrm{Ca}^{2+}$ by $18 \mathrm{C} 6$ is insignificant [51]. The fractional abundance of each calcium-bound species was calculated at the concentration of total calcium and total calmodulin used in our experiments [43]. The predominant species expected in solution is calmodulin + $2 \mathrm{Ca}^{2+}(46.7 \%)$, followed by calmodulin $+3 \mathrm{Ca}^{2+}$ 

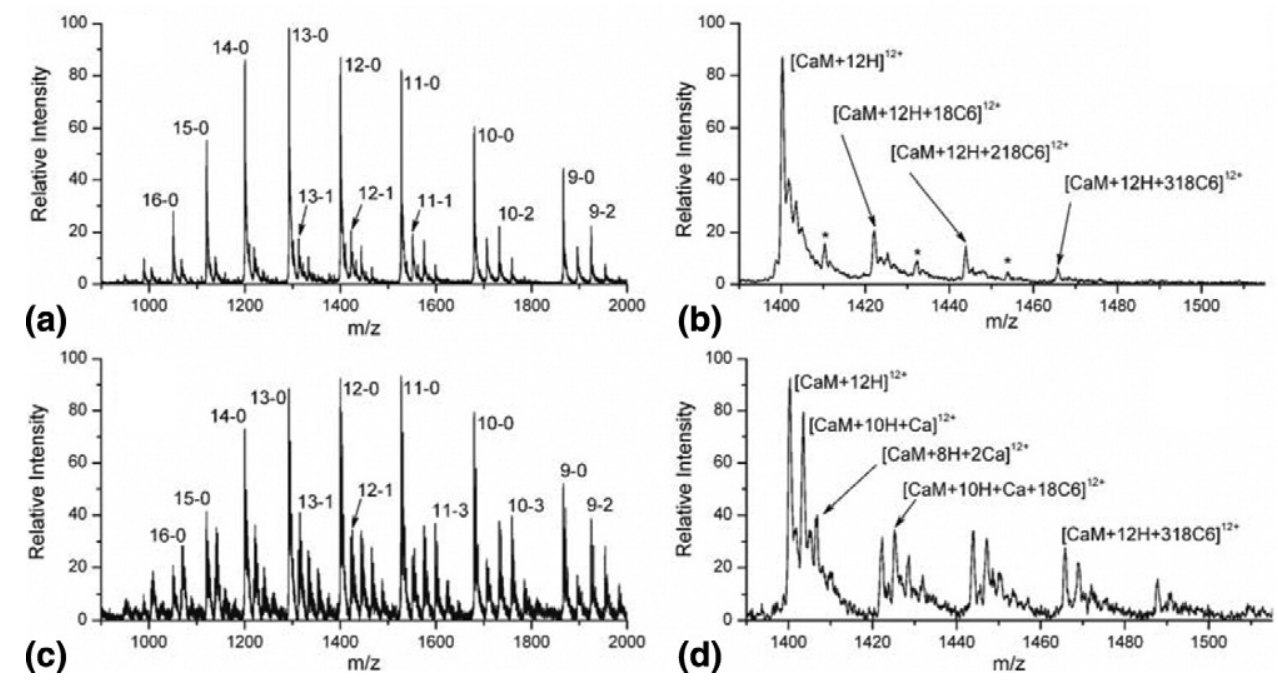

Figure 1. (a) ESI-MS of solution of calmodulin $(\mathrm{CaM})$ and $18 \mathrm{C} 6$ in $\mathrm{H}_{2} \mathrm{O}$. (b) Close-up of the +12 charge state region of Figure 1a. Asterisks indicate CaM dimer-18C6 adduct peaks. (c) ESI-MS of calmodulin, $18 \mathrm{C} 6$ and $25 \mu \mathrm{M} \mathrm{Ca}^{2+}$ in $\mathrm{H}_{2} \mathrm{O}$. Comparison between apo and holo solution show an increase in $18 \mathrm{C} 6$ attachment in holocalmodulin indicating a structural change has occurred. (d) Close-up of the +12 charge state region of the spectra shown in Figure 1c, revealing peaks corresponding to both attachment of $18 \mathrm{C} 6$ and $\mathrm{Ca}^{2+}$. The ESI-MS results do not match the $\mathrm{Ca}^{2+}$ binding stoichiometry in solution, suggesting loss of $\mathrm{Ca}^{2+}$ ions occur during ESI. Labels correspond to (charge state) - (\# 18C6s attached).

(29.6\%), calmodulin $+4 \mathrm{Ca}^{2+}(15.0 \%)$, calmodulin + $1 \mathrm{Ca}^{2+}(5.8 \%)$, and apocalmodulin $(2.9 \%)$. Of the total calcium in solution, only $0.8 \%$ is not bound to calmodulin. In theory, free calcium might hinder 18C6 binding to lysine; however, the concentration of free calcium in solution is over two orders of magnitude lower than the concentration of $18 \mathrm{C} 6$ and is therefore not expected to interfere.

Figure 1c shows the ESI mass spectrum for the solution containing calmodulin, $\mathrm{Ca}^{2+}$, and 18C6. Even cursory comparison with Figure 1a reveals significant differences between the two spectra. Closer examination, as shown in Figure 1d, reveals additional peaks corresponding to $\mathrm{Ca}^{2+}$ adducts. In contrast to what is expected in solution, apocalmodulin remains the largest peak in the spectrum with a maximum observed binding stoichiometry of calmodulin $+3 \mathrm{Ca}^{2+}$. This discrepancy has been observed previously in ESI-MS experiments [55] and is due to loss of $\mathrm{Ca}^{2+}$ during the final stages of the desolvation process. Water is an essential ligand in the $\mathrm{Ca}^{2+}$ coordination shell when bound to the protein [1]; therefore, it is not surprising that desolvation in the ESI source destabilizes $\mathrm{Ca}^{2+}$ binding. Importantly, the loss of $\mathrm{Ca}^{2+}$ does not lead to a substantial shift in the SNAPP distributions because there is not enough time for the protein to unfold and 18C6 to re-equilibrate before fully desolvated ions are formed. Once the protein is largely desolvated, the 18C6/lysine interaction becomes very strong and the SNAPP distribution is not likely to undergo further changes.

Additional insight can be extracted by examining adduct distributions for individual charge states. The filled bars in Figure 2 show SNAPP distributions taken from the mass spectrum for the +11 through +14 charge states for apocalmodulin sampled from water. For straightforward comparison, adduct distributions sampled from $\mathrm{Ca}^{2+}$ solution (open and hatched bars) are shown alongside the distributions sampled from water. The appearance of $\mathrm{Ca}^{2+}$-protein complexes in the mass spectra provides an additional level of information because now there are superimposed adduct distributions involving protein and both $18 \mathrm{C} 6$ and $\mathrm{Ca}^{2+}$.

The gas-phase [Calmodulin $+\mathrm{nH}]^{n+}$ ions sampled from $\mathrm{Ca}^{2+}$ solution are produced from a mixture of apocalmodulin and calmodulin- $\mathrm{Ca}^{2+}$ complexes where $\mathrm{Ca}^{2+}$ has been selectively lost during ESI. By mass spectrometry alone, these isobaric ions are indistinguishable. However, addition of 18C6 reveals intriguing differences between [calmodulin $+\mathrm{nH}]^{n+}$ ions sampled from water and $\mathrm{Ca}^{2+}$ solution. As shown in Figure 2 , the SNAPP distributions for [Calmodulin $+\mathrm{nH}]^{n+}$ from $\mathrm{Ca}^{2+}$ solution (open bars) show an increase both in intensity and number of 18C6 adducts compared to data obtained from water (filled bars). These results suggest that the solution phase conformations of calmodulin- $\mathrm{Ca}^{2+}$ complexes have increased lysine availability compared with apocalmodulin. Furthermore, observation of the protein-metal complex is not required to view a conformational change using SNAPP-MS, as is easily confirmed by inspection of the isobaric filled and open bars in Figure 2, which both correspond by mass to apocalmodulin. This is a significant advantage in using SNAPP for monitoring ligandbinding events because many protein-ligand complexes may be destabilized during desolvation, resulting in 

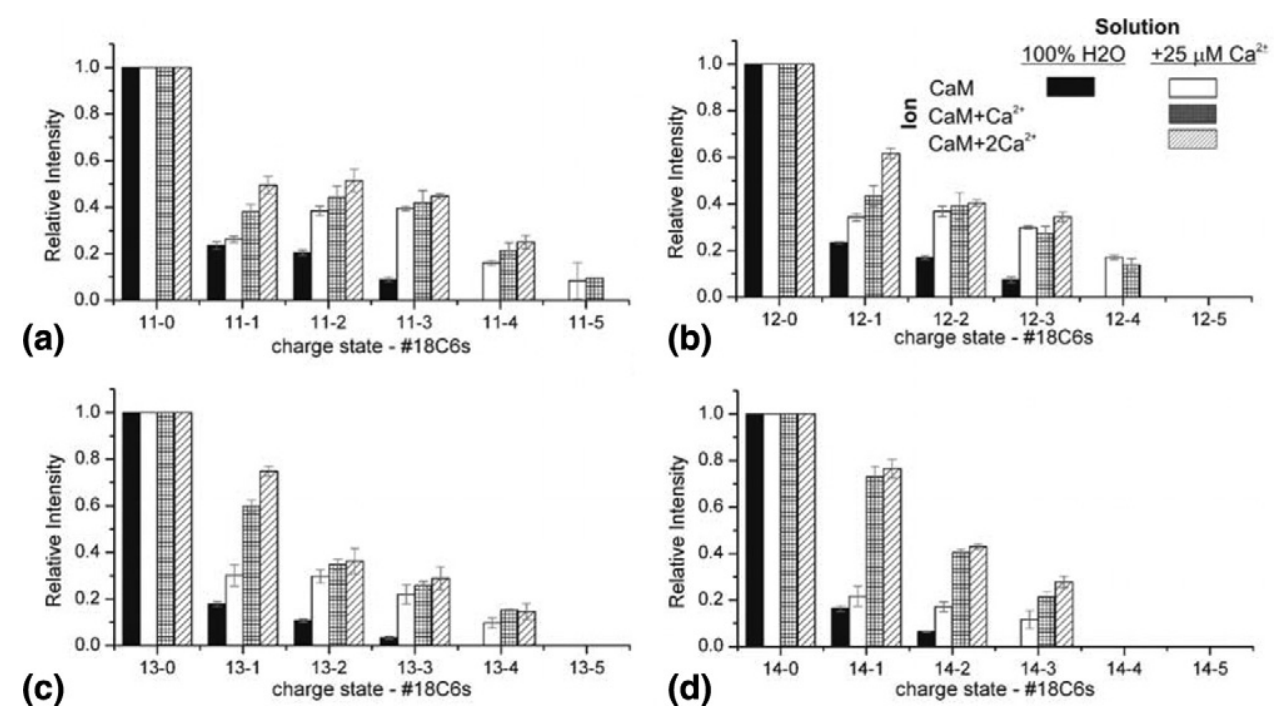

Figure 2. Extracted $18 \mathrm{C} 6$ distributions for $+11(\mathbf{a}),+12(\mathbf{b}),+13(\mathbf{c})$, and $+14(\mathbf{d})$ from spectra shown
in Figure 1. Addition of $\mathrm{Ca}^{2+}$ in solution increases the number and intensity of $18 \mathrm{C} 6$-calmodulin
complexes. Ions retaining $\mathrm{Ca}^{2+}$ in the gas phase have $18 \mathrm{C} 6$ distributions shifted towards more $18 \mathrm{C} 6$
adducts attached compared with apocalmodulin. The significant change in $18 \mathrm{C} 6$ distributions permits
detection of protein-metal ligand interaction. X-axis labels correspond to (charge state) - (\# 18C6s
attached).

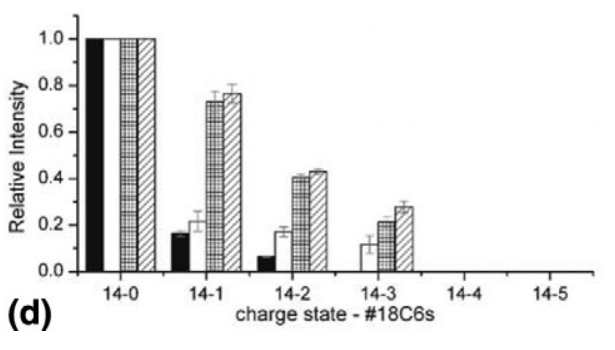

ions that are apoprotein by mass, but structurally originate from holoprotein conformations in solution.

The number of $18 \mathrm{C} 6$ adducts also increases with additional calcium adducts (see hatched bars in Figure 2). These increases are due to the greater proportion of holocalmodulin versus apocalmodulin contributing to the SNAPP distributions. For example, the [Calmodulin $+1 \mathrm{Ca}^{2+}$ ] ion may arise from ESI of Calmodulin + $1 \mathrm{Ca}^{2+}$ in solution and also loss of $\mathrm{Ca}^{2+}$ from [Calmodulin $\left.+n \mathrm{Ca}^{2+}\right](n>1)$, where greater structural rearrangement is expected. Thus, the peak assignment provides only a lower limit on the $\mathrm{Ca}^{2+}$ stoichiometry of the calmodulin- $\mathrm{Ca}^{2+}$ complex sampled from solution.

Acidic residues in the EF-hand motifs of calmodulin provide six out of the seven essential oxygen ligands to bind $\mathrm{Ca}^{2+}$. In the absence of $\mathrm{Ca}^{2+}$, these acidic residues may be hydrogen-bonded or salt-bridged to nearby positively charged residues such as lysine and arginine. To examine whether addition of $\mathrm{Ca}^{2+}$ changes intramolecular interactions involving lysine, we compared the X-ray crystal structures of apocalmodulin and holocalmodulin. Table 1 lists the average nearest heteroatom distance measured for each lysine. These distances are a coarse measure of the local environment surrounding each lysine. If a hydrogen bond acceptor is within $\sim 3 \AA$ of a lysine, 18C6 attachment will likely be hindered. In particular, it has been demonstrated previously that lysines in salt-bridges are unavailable for 18C6 attachment [48]. The average nearest heteroatom distance for every lysine either increases or remains unchanged upon addition of $\mathrm{Ca}^{2+}$, except for Lys30, which decreases from 3.70 to $2.91 \AA$. Based on this analysis, an increase in lysine availability is expected for holocalmodulin compared with apocalmodulin (in agreement with the experimental results). Closer inspection of the crystal structure for apocalmodulin reveals that two lysines, Lys21 and Lys94, are salt-bridged to E31 and E104, respectively, which are residues involved in $\mathrm{Ca}^{2+}$ binding. Addition of $\mathrm{Ca}^{2+}$ displaces lysine, which should increase lysine availability. In fact, closer examination reveals that the intramolecular interactions for Lys21 and Lys94 change significantly. Zoomed-in views of Lys94 in the crystal structures for apo- and holocalmodulin are shown in Figure 3 and highlight the changes in side-chain interactions due to calcium binding. Instead of being salt-bridged to E104 in the apo structure as seen in Figure 3a, Lys94 is freely available for 18C6 attachment in the holo structure (Figure 3b). Lys21 is no longer salt-bridged to E31 in holocalmodulin. Instead, Lys21 is hydrogen-bonded to the side-chain of Thr29, which is also expected to be less competitive towards 18 C6 binding. The changes observed in these X-ray

Table 1. Distance to nearest heteroatom neighbor for each lysine in calmodulin ${ }^{\mathrm{a}}$

\begin{tabular}{lcc}
\hline & apoCaM & holoCaM \\
\hline \hline & $10 \times 5[54]$ & $3 C L N[1]$ \\
LYS13 & 3.66 & 5.18 \\
LYS21 & 2.91 & 2.60 \\
LYS30 & 3.70 & 2.91 \\
LYS75 & 3.27 & 4.84 \\
LYS77 & 4.51 & 5.46 \\
LYS94 & 3.14 & 5.66 \\
LYS115 & 6.26 & 6.74 \\
LYS148 & $\mathrm{n} / \mathrm{a}^{\mathrm{b}}$ & $\mathrm{n} / \mathrm{a}^{\mathrm{b}}$ \\
\hline
\end{tabular}

a $10 \times 5$ and $3 C L N$ are Protein Data Bank accession IDs. bNo electron density found. 


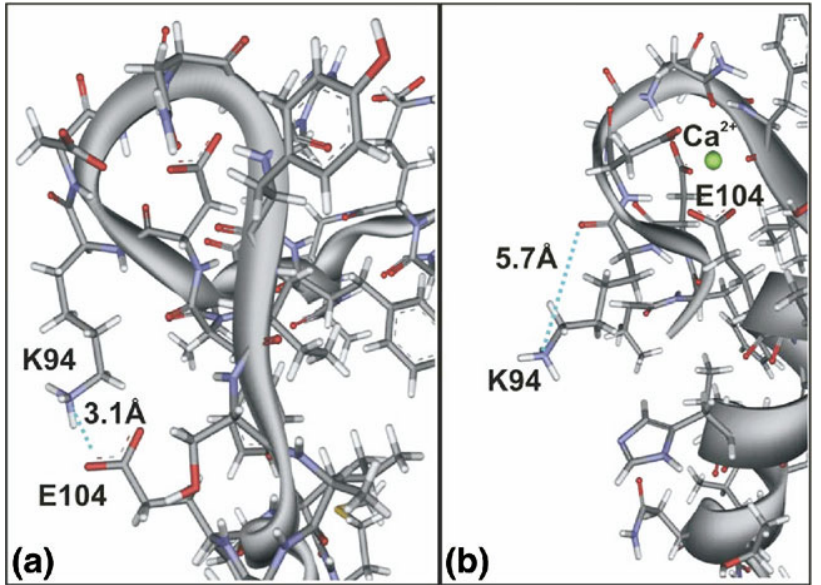

Figure 3. Partial view of the crystal structure of apo-calmodulin (a), PDB ID: 1QX5, highlighting the side-chain interactions of Lys94. Note that the side-chain of Lys94 is salt-bridged to E104. In the crystal structure of holocalmodulin (b), PDB ID: 3CLN, the calcium (in green) displaces Lys94 from the intramolecular saltbridge to coordinate with E104. Lys94 is then freely available to attach $18 \mathrm{C} 6$.

structures are consistent with our observation that lysine availability increases upon $\mathrm{Ca}^{2+}$ binding and is further evidence that SNAPP-MS samples solution phase structure. Increases in lysine availability due to the presence of metal may be an indication that the metal binding chemistry involves acidic side-chains. However, further work would be required to confirm this hypothesis.

\section{$\alpha$-Synuclein}

An important question in the pathology of Parkinson's disease is how normally benign $\alpha$-synuclein proteins aggregate. An existing theory paralleled in other amyloidogenic diseases, such as Alzheimer's disease [12], is that a conformational change occurs due to metal ligand binding $[59,60]$. Fink et al. demonstrated that out of 15 metal cations studied, $\mathrm{Al}^{3+}$ accelerated fibril formation the most and caused conformational changes detectable by intrinsic protein fluorescence and far UV-circular dichroism [11]. The acidic C-terminal domain was proposed as the binding site for $\mathrm{Al}^{3+}$. Metal binding is thought to interfere with autoinhibitory interactions between the $\mathrm{N}$ - and C-termini, which protect the central hydrophobic domain from interacting with other $\alpha$-synuclein proteins to form oligomers [10, 61]. Although this result is a significant step in understanding the metallochemistry of $\alpha$-synuclein, the biological relevance of the high $\mathrm{Al}^{3+}$ concentrations $(0.1-1 \mathrm{mM})$ required to induce observable changes in conformation and fibril formation is questionable [62].

We have examined whether $\alpha$-synuclein binds $\mathrm{Al}^{3+}$ by comparing $18 \mathrm{C} 6$ attachment to $\alpha$-synuclein in the presence and absence of $\mathrm{Al}^{3+}$ in solution. Figure 4a shows the mass spectrum of $\alpha$-synuclein and 18C6 in water. SNAPP distributions for the $+13,+16,+17$, and
+18 charge states of $\alpha$-synuclein in water are shown in Figure 5 (filled bars). The maximum number of $18 \mathrm{C} 6 \mathrm{~s}$ attached is eight, about half $(8 / 15)$ of the lysines present in the amino acid sequence of $\alpha$-synuclein. Cytochrome $c$, which is similar to $\alpha$-synuclein in molecular weight and number of lysines, binds only three 18C6s under similar conditions [48], presumably due to higher order structure that prevents $18 \mathrm{C} 6$ attachment. The 18C6 distribution for the +13 charge state has maximal intensity at 13-1, or protein with two adducts attached. At higher charge states, the distributions shift to higher numbers of 18C6s. We can quantitatively compare the distributions by calculating the average number of
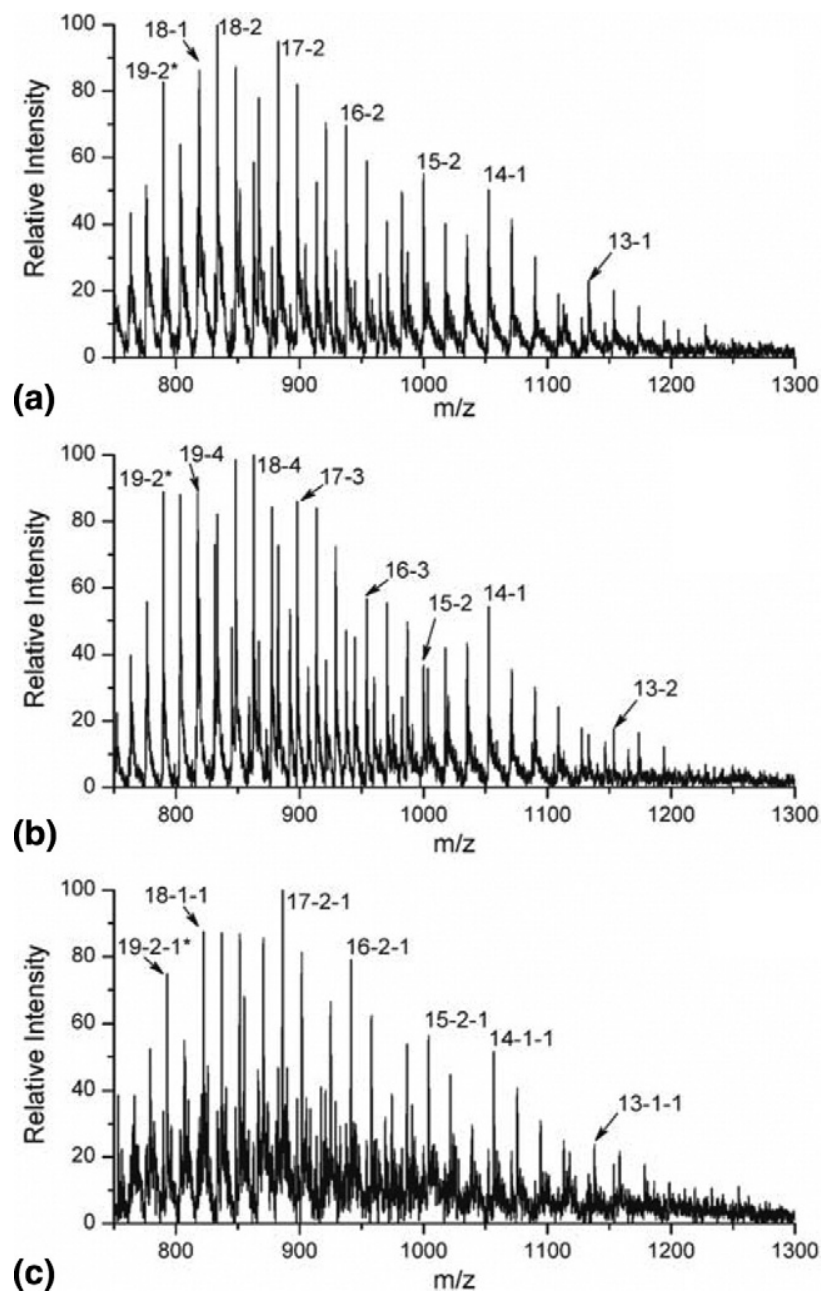

Figure 4. Mass spectra of electrosprayed solutions of $\alpha$-synuclein in water (a), in $3 \mu \mathrm{M} \mathrm{AlCl}$ (b), and in $100 \mu \mathrm{M} \mathrm{CuCl}_{2}$ (c). The charge state distribution for $\alpha$-synuclein sampled from each solution is broad, which is consistent with a natively disordered protein. The 18C6 distributions for $\alpha$-synuclein in the presence of aluminum are significantly different from water and indicates a shift in the protein dynamics. In contrast, the charge state distribution is insensitive to the effects of aluminum or copper on $\alpha$-synuclein. The labels in (a) and (b) correspond to (charge state) (\# 18C6s attached). $\mathrm{Cu}^{2+}$-protein adducts are observed in (c), thus peaks are labeled (charge state) - (\# 18C6s attached) - (\# $\mathrm{Ca}^{2+}$ attached). An asterisk indicates that the peak assignment is ambiguous due to an $\mathrm{m} / \mathrm{z}$ overlap with the 18C6 distribution of another charge state. 

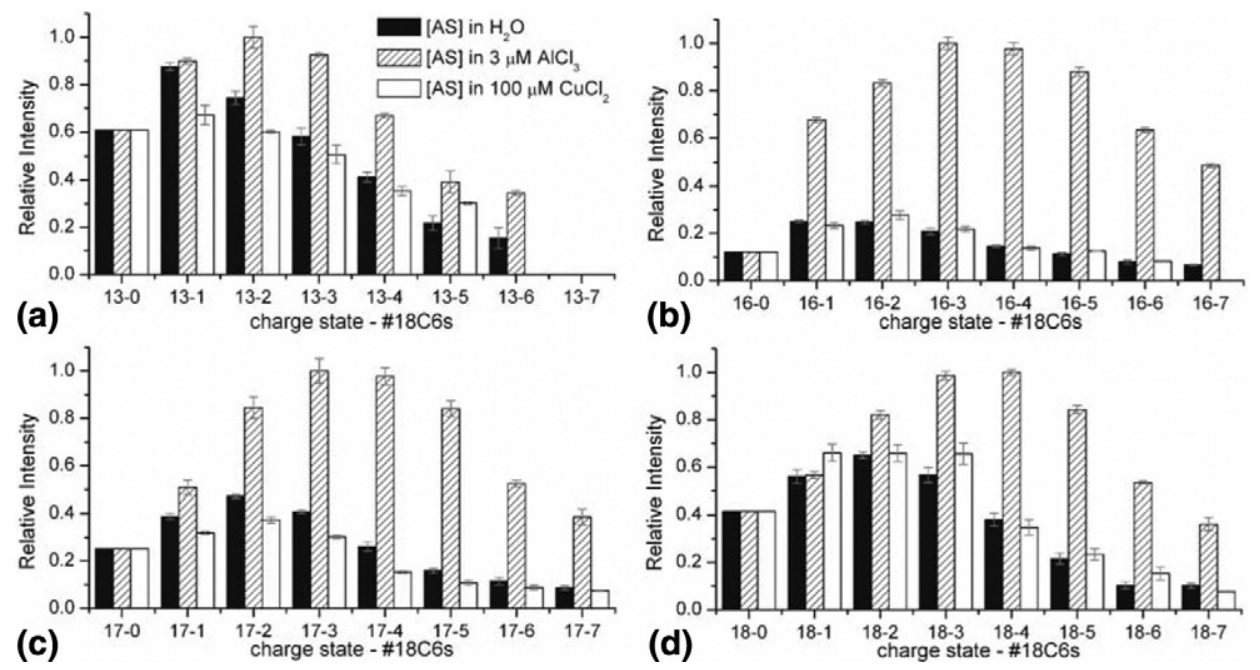

Figure 5. $18 \mathrm{C} 6$ distributions for $\alpha$-synuclein are shown for the $+13(\mathbf{a}),+16(\mathbf{b}),+17(\mathbf{c})$, and +18 (d) charge states in water (filled bars) and in $3 \mu \mathrm{M} \mathrm{Al}^{3+}$ (hatched bars). A shift towards increased 18C6 attachment occurs for the $\alpha$-synuclein ion upon addition $\mathrm{Al}^{3+}$ to solution. Addition of $100 \mu \mathrm{M} \mathrm{Cu}^{2+}$ produces protein- $\mathrm{Cu}^{2+}$ adducts, with $\left[\alpha\right.$-synuclein $\left.+\mathrm{Cu}^{2+}\right]$ being dominant. 18C6 distributions are shown for the $\left[\alpha\right.$-synuclein $\left.+\mathrm{Cu}^{2+}\right]$ (open bars), which show only minor changes relative to $\alpha$-synuclein sampled from water.

18C6s bound. For the +13 charge state, the average number of $18 \mathrm{C} 6 \mathrm{~s}$ attached is $2.16 \pm 0.04$. Higher charge states have a higher number of $18 \mathrm{C} 6 \mathrm{~s}$ bound, which are given in parentheses: $+16(2.81 \pm 0.05),+17(2.66 \pm$ $0.03),+18(2.50 \pm 0.05)$. Interestingly, the $18 \mathrm{C} 6$ binding reaches a maximum at the +16 charge state and then decreases slightly with increasing charge. These data suggest that the conformations populated in these charge states have different lysine availabilities, and imply the existence of a heterogeneous ensemble of conformations in solution. Assuming that conformations have varying propensities towards protonation due to differences in repulsive Coulombic interactions, the 18C6 distributions that are resolvable by charge state represent different dynamic states of the protein. The wide charge state distribution observed for $\alpha$-synuclein (from +11 to +20 ) is also consistent with a heterogeneous population of conformers. However, changes to the $18 \mathrm{C} 6$ distributions upon metal binding shown below reveal that these 18C6 distributions are more sensitive structural probes than examining charge states alone. Indeed, addition of metal cations does not significantly change the charge state distribution of the protein, but does significantly affect the $18 \mathrm{C} 6$ distributions.

ESI-MS of $\alpha$-synuclein and 18C6 in the presence of 3 $\mu \mathrm{M} \mathrm{Al}^{3+}$ does not produce any observable $\mathrm{Al}^{3+}$ adducts in the gas phase, as seen in Figure $4 \mathrm{~b}$. The absence of protein-metal complexes in the gas phase does not preclude their presence in solution, due to destabilization of protein-metal complexes during desolvation. However, we are still able to monitor the effects of $\mathrm{Al}^{3+}$ by examining the $18 \mathrm{C} 6$ distributions for the apo $\alpha$-synuclein ion. At $3 \mu \mathrm{M} \mathrm{Al}^{3+}$, we observe that the 18C6 distributions for $\alpha$-synuclein dramatically shift towards more adducts, as shown in the hatched bars in Figure 5. However, the magnitude of the increase is charge state-dependent. The average number of $18 \mathrm{C} 6 \mathrm{~s}$ that bind to $\alpha$-synuclein in the presence of $\mathrm{Al}^{3+}$ are as follows: $+13(2.56 \pm 0.04),+16(3.72 \pm 0.03),+17(3.59 \pm$ $0.01),+18(3.46 \pm 0.01)$. Like in water, $18 \mathrm{C} 6$ binding reaches a maximum at the +16 charge state. For the $+16,+17$, and +18 charge states, addition of $\mathrm{Al}^{3+}$ increases the average number of $18 \mathrm{C} 6 \mathrm{~s}$ by approximately one. The +13 charge state is affected less by $\mathrm{Al}^{3+}$, having an increase of $\sim 0.4$ only.

These results suggest that the effect of $\mathrm{Al}^{3+}$ binding on the structure of $\alpha$-synuclein varies as a function of conformational state. It is known that accelerated fibril formation occurs by favoring a partially folded intermediate that is on-pathway to aggregation [11]. Our results suggest that increased aggregation by $\mathrm{Al}^{3+}$ may be due to structural perturbations to only a fraction of $\alpha$-synuclein conformations. These results are also consistent with attachment to the C-terminal domain, where $\mathrm{Al}^{3+}$ binding may displace lysines involved in intramolecular interactions with acidic side-chains. The absence of arginine residues in $\alpha$-synuclein means that any intramolecular salt-bridge interaction will most likely involve an acidic residue and lysine. Interestingly, 11 out of the 15 lysines of $\alpha$-synuclein reside on the N-terminal domain, while 15 out of 24 acidic residues are on the $\mathrm{C}$-terminal tail. The SNAPP results with $\mathrm{Al}^{3+}$ are consistent with a model where transient interactions occur between the acidic C-terminal tail and lysine side-chains on the N-terminal portion of the protein. These long-range contacts have been proposed previously, and are thought to protect the central hydrophobic domain of $\alpha$-synuclein from intermolecular interactions that lead to aggregation [60]. Binding of 
$\mathrm{Al}^{3+}$ to the acidic domain prevents these transient salt-bridges, effectively increasing the availability of the lysine side-chains towards 18C6 attachment.

Copper(II) ions also accelerate fibril formation of $\alpha$-synuclein [11]. $\mathrm{Cu}^{2+}$ was found in previous work to interact with the $\mathrm{N}$-terminal domain of $\alpha$-synuclein [25]. Specifically, there is evidence that $\mathrm{Cu}^{2+}$ binds to His50 and at least one other nitrogen ligand, provided either by the amide backbone or by the $\mathrm{N}$-terminus. $\alpha$-Synuclein also contains multiple nonspecific $\mathrm{Cu}^{2+}$ binding sites with low affinity located on the C-terminal domain $[25,63]$.

ESI-MS of protein, $18 \mathrm{C} 6$, and $100 \mu \mathrm{M} \mathrm{Cu}^{2+}$ in water produces peaks corresponding to mixed complexes of $\alpha$-synuclein, $18 \mathrm{C} 6$, and $\mathrm{Cu}^{2+}$. The corresponding mass spectrum is shown in Figure 4c. Here, the interactions between $\alpha$-synuclein and metal are retained in the gas phase. $\alpha$-Synuclein $+\mathrm{Cu}^{2+}$ is the dominant copper adduct in the mass spectrum, consistent with a single high affinity binding site. The SNAPP distributions for the $\left[\alpha\right.$-synuclein $\left.+1 \mathrm{Cu}^{2+}\right]$ ion are shown in open bars in Figure 5. Comparison with the distributions from $\alpha$-synuclein in water reveals that protein complexation with $\mathrm{Cu}^{2+}$ changes the 18C6 adduct distributions slightly, but these differences are within error for most peaks, suggesting that the $\alpha$-synuclein conformations in both solutions are structurally similar. More information is revealed by examination of the shapes of the $18 \mathrm{C} 6$ distributions. For the +13 and +17 charge states, the $18 \mathrm{C} 6$ distributions for $\alpha$-synuclein $+1 \mathrm{Cu}^{2+}$ are less intense compared with $\alpha$-synuclein. The +16 charge state shows little change, while distributions for the +18 charge state increase compared with the distributions for $\alpha$-synuclein. Lower concentrations of copper produced SNAPP distributions with no significant deviations from the SNAPP distributions obtained in water. These results suggest that $18 \mathrm{C} 6$ binding is unaffected by differences in ionic strength at these concentrations of metal ion. In addition, copper adducts are no longer observed at low $\mu \mathrm{M}$ concentrations.

The limited effect of copper on the SNAPP distributions indicates that copper does not significantly affect the lysine availability of $\alpha$-synuclein. Possibly copper causes a substantial structural rearrangement which leads to no net change in lysine availability and is therefore difficult to detect. This explanation is deemed unlikely due to the high sensitivity of SNAPP to structural change. The results are more consistent with a scenario where copper attachment does not play a significant role in altering the structure of monomeric $\alpha$-synuclein. Since copper is known to facilitate fibril formation, this suggests that copper may serve to stabilize higher order aggregates, which might otherwise dissociate back into monomeric form. This hypothesis is consistent with previous observations demonstrating that the hydrodynamic radius of the protein and the chemical shifts of the backbone amide groups do not change upon $\mathrm{Cu}^{2+}$ binding $[25,60]$. Additionally, no changes in secondary structure are observed in the far UV-circular dichroism spectrum [64].

\section{Conclusions}

The interactions between $\mathrm{Ca}^{2+}$ and calmodulin were explored with SNAPP-MS. The SNAPP distributions revealed a significant conformational change due to $\mathrm{Ca}^{2+}$ binding, resulting in an increase in the overall intensity and number of 18C6 adducts attached to calmodulin. Inspection of the crystal structures for apoand holocalmodulin suggests that Lys94 and Lys 21 are key residues in producing the observed increase in lysine availability. Importantly, structural changes are still detected in the SNAPP distributions even when the calcium adducts are lost during ESI, meaning that gas-phase retention of the solution-phase ligand is not required. In general, this example reveals that SNAPP-MS is an excellent method for probing ligand binding events that involve structural rearrangement of the host protein.

In addition, SNAPP-MS was used to examine the less established metal binding properties of $\alpha$-synuclein. Our results demonstrate that $\alpha$-synuclein undergoes significant structural changes in the presence of biologically relevant concentrations of $\mathrm{Al}^{3+}$ [61]. Interestingly, there is a charge state dependence on the magnitude of the structural change, suggesting that select conformations of $\alpha$-synuclein are affected more substantially than others. These results give rise to the hypothesis that aluminum-induced acceleration of fibril formation may proceed through only a limited set of conformations. Additionally, experiments with $\mathrm{Cu}^{2+}$ suggest that significant structural changes do not occur upon $\mathrm{Cu}^{2+}$ binding. These results are consistent with complementary spectroscopic studies showing that binding of $\mathrm{Cu}^{2+}$ does not perturb the conformational dynamics of $\alpha$-synuclein. We propose that $\mathrm{Cu}^{2+}$ binding may only stabilize the structure of higher order aggregates without significant impact on the monomer. However, $\mathrm{Al}^{3+}$ clearly causes a significant perturbation in the conformations adopted by monomeric $\alpha$-synuclein, which may enable aggregation by essentially generating aggregate prone monomers.

\section{Acknowledgments}

The authors thank the American Society for Mass Spectrometry and the University of California for funding.

\section{References}

1. Babu, Y. S.; Bugg, C. E.; Cook, W. J. Structure of Calmodulin Refined at 2.2 Å Resolution. J. Mol. Biol. 1988, 204, 191-204.

2. Klee, C. B.; Vanaman, T. C. Calmodulin. Adv. Prot. Chem. 1982, 35, 213-321.

3. Walsh, D. M.; Hartley, D. M.; Kusumoto, Y.; Fezoui, Y.; Condron, M. M.; Lomakin, A.; Benedek, G. B.; Selkoe, D. J.; Teplow, D. B. Amyloid $\beta$-Protein Fibrillogenesis-Structure and Biological Activity of Protofibrillar Intermediates. J. Biol. Chem. 1999, 274, 25945-25952.

4. Conway, K. A.; Lee, S. J.; Rochet, J. C.; Ding, T. T.; Williamson, R. E.; Lansbury, P. T. Acceleration of Oligomerization, not Fibrillization, is a Shared Property of Both $\alpha$-Synuclein Mutations Linked to Early-Onset 
Parkinson's Disease: Implications for Pathogenesis and Therapy. Proc. Natl. Acad. Sci. U.S.A. 2000, 97, 571-576.

5. Prusiner, S. B. Prions. Proc. Natl. Acad. Sci. U.S.A. 1998, 95, 13363-13383.

6. Wood, S. J.; Wypych, J.; Stevenson, S.; Louis, J. C.; Citron, M.; Biere, A. L. $\alpha$-Synuclein Fibrillogenesis is Nucleation-Dependent-Implications for the Pathogenesis of Parkinson's Disease. J. Biol. Chem. 1999, 274, 19509-19512.

7. El-Agnaf, O. M. A.; Jakes, R.; Curran, M. D.; Wallace, A. Effects of Mutations $\mathrm{Ala}(3)$ to Pro and $\mathrm{Ala}(53)$ to $\mathrm{Thr}$ on the Physical and Morphological Properties of $\alpha$-Synuclein Protein Implicated in Parkinson's Disease. FEBS Lett. 1998, 440, 67-70.

8. Krishnan, S.; Chi, E. Y.; Wood, S. J.; Kendrick, B. S.; Li, C.; GarzonRodriguez, W.; Wypych, J.; Randolph, T. W.; Narhi, L. O.; Biere, A. L.; Citron, M.; Carpenter, J. F. Oxidative Dimer Formation is the Critical Rate-Limiting Step for Parkinson's Disease $\alpha$-Synuclein Fibrillogenesis. Biochemistry 2003, 42, 829-837.

9. Adlard, P. A.; Bush, A. I. Metals and Alzheimer's Disease. J. Alzheimers Dis. 2006, 10, 145-163.

10. Wright, J. A.; Brown, D. R. $\alpha$-Synuclein and Its role in metal binding: Relevance to Parkinson's Disease. J. Neurosci. Res. 2008, 86, 496-503.

11. Uversky, V. N.; Li, J.; Fink, A. L. Metal-Triggered Structural Transformations, Aggregation, and Fibrillation of Human $\alpha$-Synuclein. J. Biol. Chem. 2001, 47, 44284-44296.

12. Bush, A. I.; Pettingell, W. H.; Multhaup, G.; Paradis, M.; Vonsattel, J.; Gusella, J. F.; Beyreuther, K.; Masters, C. L.; Tanzi, R. E. Rapid Induction of Alzheimer A-B Amyloid Formation by Zinc. Science 1994, 265, 1464-1467.

13. Dawson, T. M.; Dawson, V. L. Molecular Pathways of Neurodegeneration in Parkinson's Disease. Science 2003, 302, 819-822

14. Shults, C. W. Lewy Bodies. Proc. Natl. Acad. Sci. U.S.A. 2006, 103, $1661-1668$.

15. Lewy, F. H. In Handbuch der Neurologie, Vol. III, Lewandowsky, M., Ed.; Springer: Berlin, 1912, p. 920-933.

16. Gibb, W. R. G.; Esiri, M. M.; Lees, A. J. Clinical and Pathological Features of Diffuse Cortical Lewy Body Disease (Lewy Body Dementia). Brain 1987, 110, 1131-1153.

17. Hansen, L.; Salmon, D.; Galasko, D.; Masliah, E.; Katzman, R.; DeTeresa, R.; Thal, L.; Pay, M. M.; Hofstetter, R.; Klauber, M.; Rice, V.; Butters, N.; Alford, M. The Lewy Body Variant of Alzheimer's Disease-a Clinical and Pathological Entity. Neurology 1990, 40, 1-8.

18. Polymeropoulos, M. H.; Lavedan, C.; Leroy, E.; Ide, S. E.; Dehajia, A.; Dutra, A.; Pike, B.; Root, H.; Rubenstein, J.; Boyer, R.; Stenroos, E. S.; Chandrasekharappa, S.; Athanassiadou, A.; Papapetropoulos, T.; Johnson, W. G.; Lazzarini, A. M.; Duvoisin, R. C.; Di Iorio, G.; Golbe, L. I.; Nussbaum, R. L. Mutation in the $\alpha$-Synuclein Gene Identified in Families with Parkinson's Disease. Science 1997, 276, 2045-2047.

19. Kruger, R.; Kuhn, W.; Muller, T.; Woitalla, D.; Graeber, M.; Kosel, S.; Przuntek, H.; Epplen, J. T.; Schols, L.; Riess, O. Ala30Pro Mutation in the Gene Encoding $\alpha$-Synuclein in Parkinson's disease. Nat. Genet. 1998, 18 , $106-108$.

20. George, J. M.; Jin, H.; Woods, W. S.; Clayton, D. F. Characterization of a Novel Protein Regulated During the Critical Period for Song Learning in the Zebra Finch. Neuron 1995, 15, 361-372.

21. Kholodilov, N. G.; Neystat, M.; Oo, T. F.; Lo, S. E.; Larsen, K. E.; Sulzer, D.; Burke, R. E. Increased Expression of Rat Synuclein in the Substantia Nigra Pars Compacta Identified by mRNA Differential Display in a Model of Developmental Target Injury. J. Neurochem. 1999, 73, 25862599.

22. Lee, M.; Hyun, D.; Halliwell, B.; Jenner, P. Effect of the Overexpression of Wild-Type or Mutant $\alpha$-Synuclein on Cell Susceptibility to Insult. J. Neurochem. 2001, 76, 998-1009.

23. Rekas, A.; Adda, C. G.; Aquilina, J. A.; Barnham, K. J.; Sunde, M.; Galatis, D.; Williamson, N. A.; Masters, C. L.; Anders, R. F.; Robinson, C. V.; Cappai, R.; Carver, J. A. Interaction of the Molecular Chaperone $\alpha$ B-Crystallin with $\alpha$-Synuclein: Effects on Amyloid Fibril Formation and Chaperone Activity. J. Mol. Bio, 2004, 340, 1167-1183.

24. Eliezer, D.; Kutluay, E.; Bussell, R, Jr.; Browne, G. Conformational Properties of $\alpha$-Synuclein in Its Free and Lipid-Associated States. J. Mol. Biol. 2001, 307, 1061-1073.

25. Rasia, R. M.; Bertoncini, C. W.; Marsh, D.; Hoyer, W.; Cherny, D.; Zweckstetter, M.; Griesinger, C.; Jovin, T. M.; Fernandez, C. O. Structural Characterization of Copper(II) Binding to $\alpha$-Synuclein: Insights into the Bioorganic Chemistry of Parkinson's Disease. Proc. Natl. Acad. Sci. U.S.A. 2005, 102, 4294-4299.

26. Lee, J. C.; Langen, R.; Hummel, P. A.; Gray, H. B.; Winkler, J. R. $\alpha$-Synuclein Structures from Fluorescence Energy-Transfer Kinetics: Implications for the Role of the Protein in Parkinson's Disease. Proc. Natl. Acad. Sci. U.S.A. 2004, 101, 16466-16471.

27. Fenn, J. B.; Mann, M.; Meng, C. K.; Wong, S. F.; Whitehouse, C. M. Electrospray Ionization for Mass Spectrometry of Large Biomolecules. Science 1989, 46, 64-71.

28. Kaltashov, I. A.; Eyles, S. Studies of Biomolecular Conformations and Conformational Dynamics by Mass Spectrometry. Mass Spectrom. Rev. 2002, 21, 37-71.

29. Abzalimov, R. R.; Frimpong, A. K.; Kaltashov, I. A. Gas-Phase Processes and Measurements of Macromolecular Properties in Solution: On the Possibility of False Positive and False Negative Signals of Protein Unfolding. Int. J. Mass Spectrom. 2006, 253, 207-216.

30. Loo, J. A.; Loo, R. R. O.; Udseth, H. R.; Edmonds, C. G.; Smith, R. D. Solvent-Induced Conformational Changes of Polypeptides Probed by Electrospray-Ionization Mass-Spectrometry. Rapid Commun. Mass Spectrom. 1991, 5, 101-105.

31. Konermann, L.; Douglas, D. J. Unfolding of Proteins Monitored by Electrospray Ionization Mass Spectrometry. A Comparison of Positive and Negative Ion Modes. J. Am. Soc. Mass Spectrom. 1998, 9, 1248-1254.

32. Dobo, A.; Kaltashov, I. A. Detection of Multiple Protein Conformationa Ensembles in Solution Via Deconvolution of Charge-State Distributions in ESI-MS. Anal. Chem. 2001, 73, 4763-4773.

33. Kaltashov, I. A.; Mohimen, A. Estimates of Protein Surface Areas in Solution by Electrospray Ionization Mass Spectrometry. Anal. Chem. 2005, 77, 5370-5379.

34. Young, M. M.; Tang, N.; Hempel, J. C.; Oshiro, C. M.; Taylor, E. W.; Kuntz, I. D.; Gibson, B. W.; Dollinger, G. High Throughput Protein Fold Identification by Using Experimental Constraints Derived from Intramolecular Cross-Links and Mass Spectrometry. Proc. Natl. Acad. Sci. U.S.A. 2000, 97, 5802-5806.

35. Kruppa, G. H.; Schoeniger, J.; Young, M. M. A Top Down Approach to Protein Structural Studies Using Chemical Cross-Linking and Fourier Transform Mass Spectrometry. Rapid Commun. Mass Spectrom. 2003, 17 155-162.

36. Pearson, K. M.; Pannell, L. K.; Fales, H. M. Intramolecular CrossLinking Experiments on Cytochrome $c$ and Ribonuclease A Using an Isotope Multiplet Method. Rapid Commun. Mass Spectrom. 2002, 16, 149-159.

37. Bennett, K. L.; Kussman, M.; Bjork, P.; Godzwon, M.; Mikkelsen, M.; Sorensen, P.; Roepstorff, P. Chemical Cross-Linking with ThiolCleavable Reagents Combined with Differential Mass Spectrometric Peptide Mapping - a Novel Approach to Assess Intermolecular Protein Contacts. Prot. Sci. 2000, 9, 1503-1518.

38. Back, J. W.; de Long, L.; Muijsers, A. O.; de Koster, C. G. Chemical Cross-Linking and Mass Spectrometry for Protein Structural Modeling. J. Mol. Biol. 2003, 331, 303-313.

39. Miranker, A.; Robinson, C. V.; Radford, S. E.; Aplin, R. T.; Dobson, C. M. Detection of Transient Protein-Folding Populations by Mass-Spectrometry. Science 1993, 262, 896-900.

40. Wagner, D. S.; Anderegg, R. J. Conformation of Cytochrome $c$ Studied by Deuterium-Exchange Electrospray-Ionization Mass-Spectrometry. Anal. Chem. 1994, 66, 706-711.

41. Katta, V.; Chait, B. T. Hydrogen-Deuterium Exchange ElectrosprayIonization Mass-Spectrometry-a Method for Probing Protein Conformational Changes in Solution. J. Am. Chem. Soc. 1993, 115, 6317-6321.

42. Mandell, J. G.; Falick, A. M.; Komives, E. A. Measurement of Amide Hydrogen Exchange by MALDI-TOF Mass Spectrometry. Anal. Chem. 1998, 70, 3987-3995.

43. Nemirovskiy, O.; Giblin, D. E.; Gross, M. L. Electrospray Ionization Mass Spectrometry and Hydrogen/Deuterium Exchange for Probing the Interaction of Calmodulin with Calcium. J. Am. Soc. Mass Spectrom. 1999, 10, 711-718

44. Zhu, M. M.; Rempel, D. L.; Zhao, J.; Giblin, D. E.; Gross, M. L. Probing $\mathrm{Ca}^{2+}$-Induced Conformational Changes in Porcine Calmodulin by H/D Exchange and ESI-MS: Effect of Cations and Ionic Strength. Biochemistry 2003, 42, 15388-15397.

45. Mendoza, V. L.; Vachet, R. W. Protein Surface Mapping Using Diethylpyrocarbonate with Mass Spectrometric Detection. Anal. Chem. 2008, 80(8), 2895-2904.

46. Friess, S. D.; Zenobi, R. Protein Structure Information from Mass Spectrometry? Selective Titration of Arginine Residues by Sulfonates. J. Am. Soc. Mass Spectrom. 2001, 12, 810-818.

47. Friess, S. D.; Daniel, J. M.; Hartmann, R.; Zenobi, R. Mass Spectrometric Noncovalent Probing of Amino Acids in Peptides and Proteins. Int. J. Mass Spectrom. 2002, 219, 269-281.

48. Ly, T.; Julian, R. R. Using ESI-MS to Probe Protein Structure by Site-Specific Noncovalent Attachment of 18-Vrown-6. J. Am. Soc. Mass Spectrom. 2006, 17, 1209-1215.

49. Liu, Z.; Cheng, S.; Gallie, D. R.; Julian, R. R. Exploring the Mechanism of Selective Noncovalent Adduct Protein Probing Mass Spectrometry Utilizing Site-Directed Mutagenesis to Examine Ubiquitin. Anal. Chem. 2008, 80, 3846-3852.

50. Ly, T.; Liu, Z.; Pujanauski, B. G.; Sarpong, R.; Julian, R. R. Surveying Ubiquitin Structure by Noncovalent Attachment of Distance Constrained Bis(Crown) Ethers. Anal. Chem. 2008, 80, 4807-5276.

51. Julian, R. R.; Beauchamp, J. L. Site Specific Sequestering and Stabilization of Charge in Peptides by Supramolecular Adduct Formation with 18-Crown-6 Ether by Way of Electrospray Ionization. Int. J. Mass Spectrom. 2001, 210, 613-623.

52. Izatt, R. M.; Pawlak, K.; Bradshaw, J. S. Bruening, R. L. Thermodynamic and Kinetic Data for Macrocycle Interaction with Cations and Anions. Chem. Rev. 1991, 91, 1721-2085.

53. Zhang, M.; Tanaka, T.; Ikura, M. Calcium Induced Conformational Transition Revealed by Solution Structure of apo-Calmodulin. Nat. Struct. Biol. 1995, 2, 758-767.

54. Kuboniwa, H.; Tjandra, N.; Grzesiek, S.; Ren, H.; Klee, C. B.; Bax, A Solution Structure of Calcium-Free Calmodulin. Nat. Struct. Biol. 1995, 2 768-776.

55. Schumacher, M. A.; Crum, M.; Miller, M. C. Crystal Structures of apo-Calmodulin and an apo-Calmodulin/SK Potassium Channel Gating Domain Complex. Structure 2004, 12, 849-860.

56. Hu, P. F.; Ye, Q. Z.; Loo, J. A. Calcium Stoichiometry Determination for Calcium-Binding Proteins by Electrospray-Ionization Mass-Spectrometry. Anal. Chem. 1994, 66, 4190-4194. 
57. Lafitte, D.; Heck, A. J. R.; Hill, T. J.; Jumel, K.; Harding, S. E.; Derrick, P. J. Evidence of Noncovalent Dimerization of Calmodulin. Eur. J. Biochem. 1999, 261, 337-344.

58. Linse, S.; Helmersson, A.; Forsén, S. Calcium Binding to Calmodulin and Its Globular Domains. J. Biol. Chem. 1991, 266, 8050-8054.

59. Paik, S. R.; Shin, H. J.; Lee, J. H.; Chang, C. S.; Kim, J. Copper(II)-Induced Selfoligomerization of $\alpha$-Synuclein. Biochem. J. 1999, 340, 821-828.

60. Paik, S. R.; Lee, J. H.; Kim, D. H.; Chang, C. S.; Kim, J. Aluminum-Induced Structural Alterations of the Precursor of the Non-A $\beta$ Component of Alzheimer's Disease Amyloid. Arch. Biochem. Biophys. 1997, 344, 325-334.

61. Binolfi, A.; Rasia, R. M.; Bertoncini, C. W.; Ceolin, M. Zweckstetter, M. Griesinger, C.; Jovin, T. M. Fernandez, C. O. Interaction of $\alpha$-Synuclein with Divalent Metal Ions Reveals Key Differences: A Link Between Structure, Binding, Specificity, and Fibrillation Enhancement. J. Am. Chem. Soc. 2006, 128, 9893-9901.

62. Corrigan, F. M.; Reynolds, G. P.; Ward, N. I. Hippocampal Tin, Aluminum, and Zinc in Alzheimer's Disease. Biometals 1993, 6, 149-154

63. Sheng, Y.; Zabrouskov, V.; Loo, J. A. Top-Down Mass Spectrometry of Noncovalent Protein Complexes for Determining Binding Sites; Proceedings of the Lake Arrowhead Ion Chemistry Conference, Lake Arrowhead, CA, January 2008.

64. Hoyer, W.; Cherny, D.; Subramaniam, V.; Jovin, T. M. Impact of the Acidic C-Terminal Region Comprising Amino Acids 109-140 on a Synuclein in Vitro. Biochemistry 2004, 43, 16233-16242. 